\title{
Traffic Accidents Analysis on Dry and Wet Road Bends Surfaces in Greater Manchester-UK
}

\author{
Karzan S. Ismael \\ Lecturer at City Planning Engineering Department \\ Technical College of Engineering \\ Sulaimani Polytechnic University \\ Sulaimani, Iraq \\ karzan.saleem@spu.edu.iq
}

\author{
Noorance A. Razzaq \\ Lecturer at Civil Engineering Department \\ University of Al-Muthanna, Iraq \\ PhD Researcher, Transport Engineering and Planning \\ Group, University of Salford, UK \\ n.a.r.al-mukaram@edu.salford.ac.uk
}

\begin{abstract}
Road accidents becomes global health and safety issues because of the gradual increase in the number of injuries and fatalities. In the UK, road accidents due to weather conditions has been one of the traffic safety challenges for researchers as well as drivers particularly in Greater Manchester. This is because of its influence on driver behaviour approaching traffic lights on the road bends. Hence, to better understand driver behaviour, this paper presents various driving behaviour on wet and dry road conditions. Data were obtained from police reports of road accidents at hazardous locations in Greater Manchester between 2011 and 2015. The reported data covers information regarding: Accidents, Vehicle, and Casualties. The obtained data was used to examine how road surface is associated with road accidents by using Chi-Square statistical test. The analysis showed that road surface significantly contributed to accidents at bend roads. Moreover, drivers' behaviour was investigated as they can be expected to have a significant impact on accident occurrence. Finally, the main goal is that these results might reflect the safety issue at bend roads.
\end{abstract}

Keywords: Road accidents, Driver behaviour, weather conditions, Hazardous locations (Bends).

\section{INTRODUCTION}

In urban areas, road traffic safety has been considered as a serious problem for society in its own right and in turn affects the capacity and efficiency of the road network. According to the World Health Organization [20], about 1.25 million people are killed on the roads and $50 \%$ of those are vulnerable road users. In addition, these accidents cost European countries between 2\% and 5\% of their Gross Domestic Product (GDP).

Consequently, many studies have been carried out to investigate the effect of different contributory factors on the frequency of road accidents. Hazard locations such as bend roads have been considered as critical areas because of its geometrical design as well as surface friction. Bend in the road can be defined as sharp curve section that a driver has to complete his/her turning at the end of the section. However, frequent accidents tend to be higher at these sections than at the normal straight roads [18]. This is true not only because of losing control and braking action but also because some drivers did not see a traffic queue or a stationary vehicle and could not stop in time and the collision was occurred. In addition, a vehicle can be hit by an oncoming vehicle because either pulling out of side roads, or traversing to the wrong side particularly on blind bends.

Moreover, Nambuusi et al. [13] concerned that the risk of rear accident at curved roads was approximately two times higher than at straight roads; and the risk could be lower during the night compared to daytime. Furthermore, the analysis confirmed that the accident risk could be increased as the speed limit increases particularly at sections provided with traffic light signals. On the other hand, studies were carried out by Edwards [5], Fu [6], Kilpeläinen and Summala [10] who illustrated that adverse climatic conditions may affect driving behaviour and road safety. For example, road accidents are more likely to occur on wet and slippery roads than dry road surfaces. This mainly can be defined as skid resistance resulting in friction force that required for stability and control of vehicle travelling on the carriageway. The friction between the tyre and road decreased at wet surfaces, however that depends on the tyre tread design, surface texture and depth of water. Therefore, this paper is focused on road safety arising from traffic accidents at road bends taking into consideration the climatic conditions. Greater Manchester was taken as a case study to find out the contributory factors affecting road safety.

\section{RELATED WORK}

Adverse climate is one of the environmental factors that is recognized to influence driver performance on the road, particularly in the case where visibility is poor the friction on the road is reduced. On the other hand, other factors such as speeding and faults in traffic signal operations have major impacts on road safety.

Many literatures have looked at driving behaviour on both dry and wet road conditions. Fu [6] demonstrated that the probability of accident occurrence can be increased as the humidity level and rainfall increased. Additionally, the research of human behaviour in traffic psychology deals with the topic of road surface conditions. Research states that speeding is one of the adverse driving behaviour which is affected by weather conditions. According to Kilpeläinen and Summala [10] adverse weather and road conditions, such as rain, snowfall and changing temperature, are significant contributors to a high risk of traffic accidents occurring. 
In addition, it has been reported that in north-western USA the maximum rainfall is a major factor contributed to higher accident percentages. The risk of accidents can be controlled at several levels. This is demonstrated by driver compensating associated with wet roads by adapting their driving behaviour; for instance, with longer headways, lower speeds, and avoidance of overtaking on two lane roads. Therefore, it would appear that the accident risk in wet conditions is higher than that in dry conditions. Nevertheless, generally, in the last few decades, positive trends have been seen in some countries, such as Finland. Figure 1 shows that the rate of accidents per vehicle kilometer in Finland has dropped gradually since 1979. In the 1980s, the investigations were begun into the control of road surface conditions and apply some speed interventions. Clearly, in the winter season the number of fatal accidents was higher compared to the summer and dry road conditions [16]. Following this, speed limits were introduced resulting in the number of fatal accidents being similar for both seasons, as shown in Figure 1.1 below.

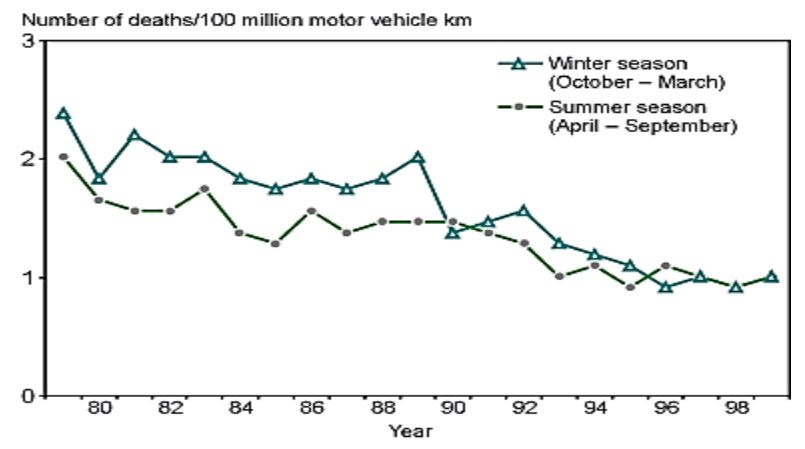

Figure 1: Risk of fatal accidents on public roads in Finland from 1979 to1999 [16].

\subsection{Accidents on wet road conditions}

In exploring the problem in West Virginia, the proportion of accidents on wet-pavement is 2.2 times the number of accidents on dry-pavement [3]. According to the Institute of Road Safety Research, the occurrence of accidents has been influenced by many factors [11]. For example, poor drainage system on road pavement may reduce the level of safety on the road. Other factors can be summarized as: the quality of the road surface, vehicle speed, and tyre type. In addition, Summala [17] confirmed that the efficiency of braking and controlling the vehicle on wet surfaces become worse than that on the dry surfaces. Greibe [7] stated that it is necessary to study the differential friction during the analysis of the pavement friction. Differential friction is a term used to explain the situation where the wheel paths on which a traveling vehicle have dissimilar friction coefficients. It has been noted that it cannot be a result of hydrodynamics, but it is due to smoothing of the surface by water which reduces the friction. In New Delhi, a case study of the influence of rainfall on road crashes concluded that approximately $16.7 \%$ of the total took place on a wet road [12].
According to Hatherly and Young [8] the larger dangers in wet weather are slipperiness of road surface and poor visibility. Based on accident data for 2014 in the UK, there were 146,322 injuries caused by 44,081 accidents on wet roads [4].

\subsection{Driver behaviour on slippery road conditions}

Identify slippery road and poor visibility of drivers are the major reasons causing an increase in the risk of accidents. Rämä [16] stated that the average speeds on a slippery road surface lower than in a good road surface conditions which are roughly $4 \mathrm{~km}$ per hour in terms of speed. Also, it was noticed that the headways are generally not influenced by wet road condition. It could be argued that the number of reasons can cause unsatisfactory adaptation of driver behaviour. There is safe driving behaviour resulting from a good relationship of three components: vehicle, driver and the road environment. The extreme changes in road surface conditions lead to more surprises to the drivers as well as his/her vehicle. Increasing friction between tyres and road surface are required in winter than in good weather conditions in order to provide effective reaction for sudden stopping. However, it is difficult because of many reasons. Firstly, drivers are not only concerned with safety; but they have several aims during their journeys. Secondly, the indicating of information for slipperiness is rarely. Thirdly, incorrect behaviour does not give sufficient feedback on the risk of low friction. Most earlier studies conducted by Keay and Simmonds [9] concerning to control movement of vehicles on the lower friction and poor road conditions. The driver could make a decision on necessary action such as increasing headway or decreasing speed while this is particularly difficult through the reduction of friction during the trip. This might be happened because of changing in temperature.

\subsection{The effect of skid resistance on road safety}

Skidding is one of the major causes of accidents on wet road surfaces [11]. The resistance between two surfaces to move is defined as friction. Friction could occur on a road during a vehicle trip at the wheel-road interface, to enable the driver to steer, accelerate and brake in order to stay on the road. It is noticed that road surface conditions, tyres, road surface characteristic and speed limit are relevant factors upon which friction is dependent. According to Pardillo Mayora and Jurado Piña [15] the crash rates show a declined trend when skid resistance values are increased for both wet and dry roads.

\section{DATA COLLECTION AND EXTRACTION METHODS}

For the purpose of this study, road accidents on the bend roads were taken from the police reports in Greater Manchester. The data was reported using number codes in STATS19 forms including details of 1074 accidents, 1931 vehicles, and 1717 causalities. Next, the data was exported to Microsoft Excel sheets 
for analysis to find out the contributory factors affecting these accidents on different road surface conditions. The analysis process includes different statistical functions such as FREQUENCY, VLOOKUP, COUNTIFS and SUMIFS in order to obtain the required information. Finally, the summarised results will be presented in graphs and tables in the following sections. Further methodological issues, an extra vital statistical provisions should be taken seriously such as Chi-Square test in order to ensure a valid analysis leading to reliable results and findings.

\section{RESULTS AND DISCUSSION}

\subsection{Frequency of accidents versus road surfaces at hazard location:}

Figure 2 shows the number of accidents. Data was reported for the last five years in different road surface conditions (dry and wet).

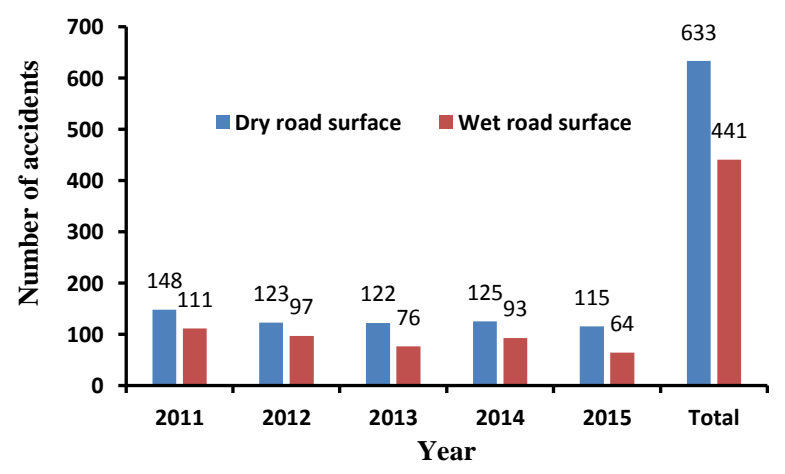

Figure 2: The distribution of accidents according to road surface conditions at hazard locations.

Also, it can be noticed that the number of accidents on dry roads was greater than the number on wet roads in the period between 2011 and 2015. The data indicate more crashes in dry conditions and more awareness of the drivers in dangerous wet conditions. In total the analysis considers about 1,074 accidents about $41 \%$ of which occurred on wet roads.

\subsection{The number of road accidents by severity at hazard location at bend roads:}

The total number of accidents in Greater Manchester involving hazard locations, such as going ahead left hand bends and going ahead right hand bends, are reported for the period 2011-2015. Figure 3 displays the levels of severity over the period. It can be shown in figure 3 that the total number of accidents was gradually reduced. In 2011, the number of accidents was 274 , then in 2012 declined to 231 accidents, and finally it decreased to 188 by 2015 (i.e. approximately $45 \%$ decrease in the total number of accidents over the 5 years). The main responsible for this reduction is the safety improvement, which can be seen by the local authority schemes over the last five years.

In addition, because these types of road accidents are commonly occurred across the United Kingdom, it is necessary to improve safety measures and promote improvement in driver behaviour. Although, improvements in accident statistics can be seen each year, the problem is still huge and needs to further investigation [14].

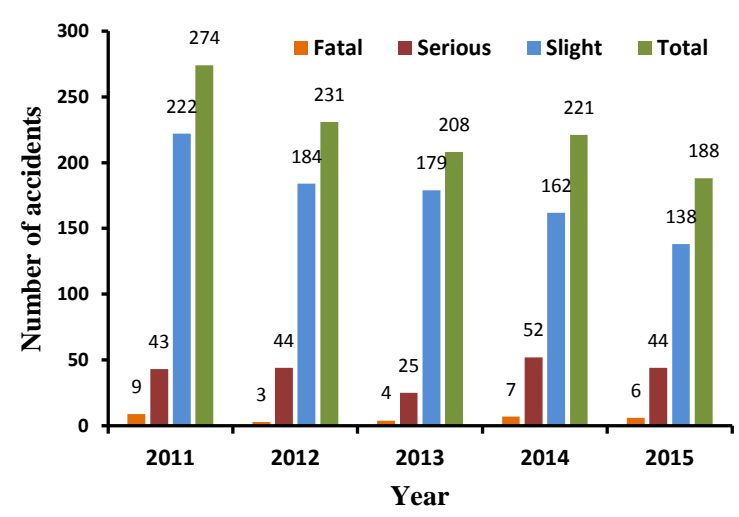

Figure 3: Reported accidents at bends in GM based on severities (2011-2015).

Many studies found that slippery road surfaces might increase the risk of fatal injury crashes. However, several studies introduced the relationship between injury severity and weather conditions. The findings were shown that during rainfall slight injuries were relatively more frequent than serious injuries.

According to Keay and Simmonds [9], the relative increase in the slight crashes can be due to reduce friction between the tyres and road surface. Following other studies, it was found that the risk of injury is higher in all cases (wet and dry conditions) suggesting that the presence of rainfall consistently represents a driving hazard. Furthermore, drivers usually maintain lower speed during rainfall. As shown in figure 3 above, the number of slightly injuries is greater than fatalities and serious injuries for both dry and wet road surfaces and number of fatalities is approximately $40 \%$ on the wet roads from the total fatalities.

A significant relationship between road surface and severity was shown in figure 4 and table 1 using Chisquare test. The null hypothesis $\left(\mathrm{H}_{0}\right)$ was assumed that there is no association between the road surface conditions (wet-dry) and levels of severity in terms of number of accidents. The total Chi-square value equals the summation of values in the table. The total calculated Chi-square value $X^{2}=0.69$. This value should be compared with the critical value from Chi-square table. The tabulated critical value is chosen according to the used which is equal to 1 . The critical value is equal to 3.84 at the $5 \%$ level of confidence and degree of freedom equal to 1 . It can be seen that the calculated Chi-square $\left(\mathrm{X}^{2}\right)$ value is by far smaller than the value of $X^{2}$ from the table (3.84). Then, the null hypothesis is accepted at $5 \%$ confidence level which highlights that there is no significant association between road surface conditions and severities. However, the total accidents on wet roads is around $40 \%$ of the total reported accidents which means the risk of involving in an accident is increasing as the pavement surface becomes wet. 
Table 1: The relationship between road surface and severity of accidents.

\begin{tabular}{|c|c|c|c|c|c|}
\hline Severity & \multicolumn{2}{|c|}{ Dry road surfaces } & \multicolumn{2}{|c|}{ Wet road surfaces } & $\begin{array}{c}\text { Total } \\
\text { observed }\end{array}$ \\
\hline \multirow{3}{*}{$\begin{array}{c}\text { Fatal and } \\
\text { serious }\end{array}$} & Observed & Expected & Observed & Expected & \multirow{2}{*}{229} \\
\hline & 141 & 134.96 & 88 & 94.04 & \\
\hline & \multicolumn{2}{|c|}{$\mathrm{X}^{2}=0.22$} & \multicolumn{2}{|c|}{$X^{2}=0.32$} & 0.54 \\
\hline \multirow{3}{*}{ Slight } & Observed & Expected & Observed & Expected & \multirow{2}{*}{845} \\
\hline & 492 & 498.04 & 353 & 346.96 & \\
\hline & \multicolumn{2}{|c|}{$X^{2}=0.06$} & \multicolumn{2}{|c|}{$\mathrm{X}^{2}=0.09$} & 0.15 \\
\hline $\begin{array}{c}\text { Total } \\
\text { observed }\end{array}$ & \multicolumn{2}{|c|}{633} & \multicolumn{2}{|c|}{441} & 1074 \\
\hline $\begin{array}{l}\text { Total Chi } \\
\text { square } \\
\text { values }\end{array}$ & \multicolumn{2}{|c|}{$X^{2}=0.28$} & \multicolumn{2}{|c|}{$X^{2}=0.41$} & 0.69 \\
\hline
\end{tabular}

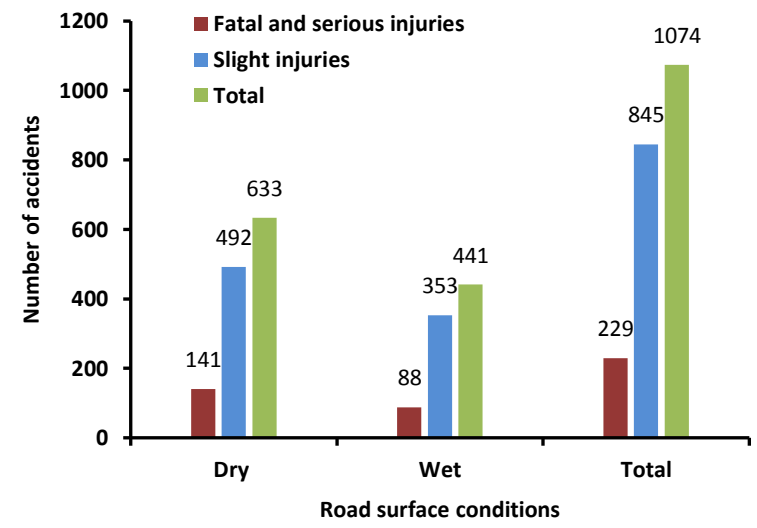

Figure 4: Road surface conditions versus severity of road accidents at bends

\subsection{The relationship between road surface conditions} and lighting conditions at bend roads:

Figure 5 illustrates the number of accidents on the dry road surfaces and in lighting conditions. On the dry roads, the proportion of accidents in daylights is higher than the proportion of accidents in dark conditions. Nevertheless, only $40 \%$ of the accidents on wet surfaces was occurred in dark conditions. This is an indication of risk of driving in wet weather condition at dark times.

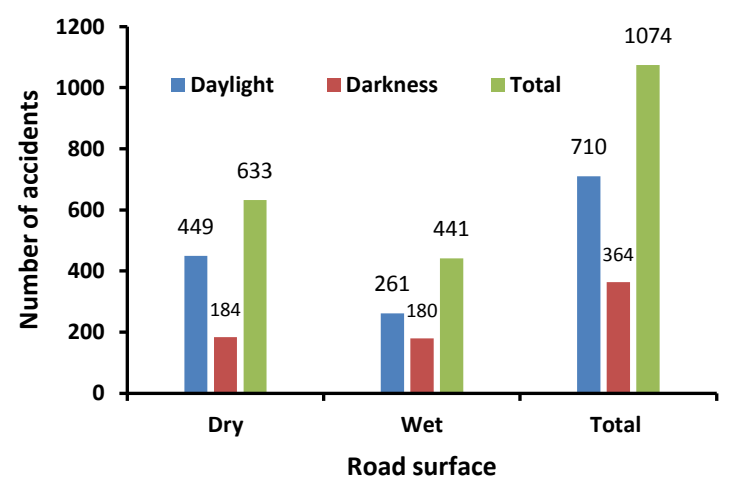

Figure 5: Road surface conditions versus lighting conditions at bend roads.

It can be concluded therefore that, the situation on wet roads gets worse at daylight than at night because of heavy traffic flow. This finding coincides with the literature reviews of Assum et al. [1] and Bassani et al. [2]. The association between road surface conditions and lighting conditions was discovered by applying the Chi-square test as shown in table 2 below. Following the previous procedures of contingency tables in order to highlight any possible association between the aforementioned factors and number of accidents. The null hypothesis $\left(\mathrm{H}_{0}\right)$ was assumed that there is no association between the road surface conditions (wetdry) and lighting conditions (daylight-darkness) in terms of number of accidents.

The calculated Chi-square $X^{2}=15$. Testing at $5 \%$ level, the critical region is $X^{2}>X^{2}{ }_{0.05}=3.84$. Then, the null hypothesis is rejected at 5\% confidence level which highlights that there is a significant association between road surface conditions and lighting conditions.

Table 2: The relationship between road surface and lighting conditions at bend roads.

\begin{tabular}{|c|c|c|c|c|c|}
\hline Lighting & \multicolumn{2}{|c|}{ Dry road surfaces } & \multicolumn{2}{|c|}{ Wet road surfaces } & Total \\
\hline \multirow{3}{*}{ Daylight } & Observed & Expected & Observed & Expected & \multirow{2}{*}{710} \\
\hline & 449 & 418.46 & 261 & 291.54 & \\
\hline & \multicolumn{2}{|c|}{$X^{2}=2.16$} & \multicolumn{2}{|c|}{$X^{2}=3.10$} & 5.26 \\
\hline \multirow{3}{*}{ Darkness } & Observed & Expected & Observed & Expected & \multirow{2}{*}{364} \\
\hline & 184 & 212.54 & 180 & 149.46 & \\
\hline & \multicolumn{2}{|c|}{$X^{2}=3.70$} & \multicolumn{2}{|c|}{$X^{2}=6.04$} & 9.74 \\
\hline $\begin{array}{c}\text { Total } \\
\text { observed }\end{array}$ & \multicolumn{2}{|c|}{633} & \multicolumn{2}{|c|}{441} & 1074 \\
\hline $\begin{array}{l}\text { Total Chi } \\
\text { square } \\
\text { values }\end{array}$ & \multicolumn{2}{|c|}{$X^{2}=5.86$} & \multicolumn{2}{|c|}{$X^{2}=9.14$} & 15 \\
\hline
\end{tabular}

4.4 The relationship between road surface conditions and road speed limit at bend roads:

Based on many literature reviews, it is expected that the number of accidents increases as speeds increase. This expectation does not seem to be valid in the following results. In contrast, it can be seen that, few frequencies of accidents occurred on high speed limit roads (> 30 mph) in both dry and wet road surfaces in comparison 
with low speed roads $(\leq 30 \mathrm{mph})$ as seen in figure 6 . This can be attributed, according to many studies, either to the increase in awareness of drivers as the speed increases, or due to the collected data including many low speed roads than high speed roads. Moreover, drivers are more careful when approaching the sharp bends. There is also can be seen that in the low speeds more drivers are involved in accidents as 921 accidents in low speed roads compared to 221 accidents in high speed roads.

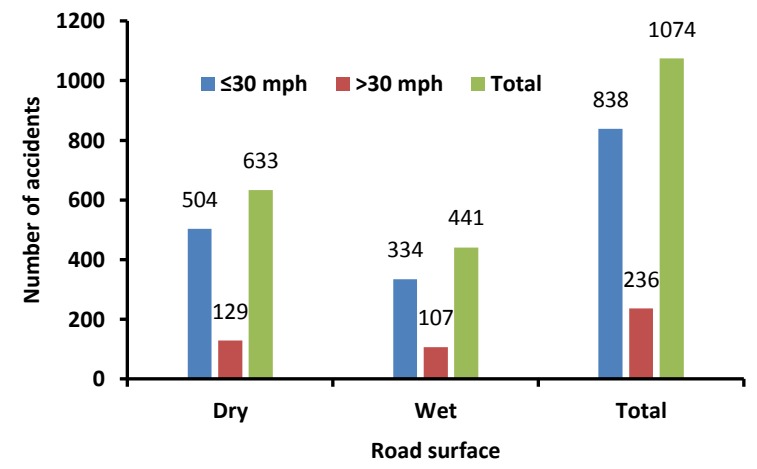

Figure 6: Road surface conditions versus speed limit at bend roads.

Table 3 aims not only to present the observed accidents but also to find out whether the road surface is associated with high accident rates. Assume the null hypothesis $\mathrm{H}_{0}$ that there is no association between the road surface conditions (wet-dry) and speed limit roads (low-high) in terms of number of accidents. For $\mathrm{H}_{0}$, the calculated Chi-square $X^{2}=2.07$. Testing at 5\% level, the critical region is $X^{2}>X_{0.05}^{2}=3.84$. Hence the calculated $\mathrm{X}^{2}<3.84$, the $\mathrm{H}_{0}$ is accepted and clearly the observed rates do not differ significantly at the $5 \%$ level, such that there is no association between surface conditions and road speed limit.

Table 3: The relationship between road surface and road speed limits.

\begin{tabular}{|c|c|c|c|c|c|}
\hline $\begin{array}{l}\text { Speed } \\
\text { limits }\end{array}$ & \multicolumn{2}{|c|}{ Dry road surfaces } & \multicolumn{2}{|c|}{ Wet road surfaces } & $\begin{array}{c}\text { Total } \\
\text { observe }\end{array}$ \\
\hline \multirow{3}{*}{$\begin{array}{c}\text { Low } \\
\text { speed } \\
\text { roads } \\
\leq 30 \mathrm{mph}\end{array}$} & Observed & Expected & Observed & Expected & \multirow{2}{*}{838} \\
\hline & 504 & 493.91 & 334 & 344.09 & \\
\hline & \multicolumn{2}{|c|}{$X^{2}=0.19$} & \multicolumn{2}{|c|}{$\mathrm{X}^{2}=0.27$} & 0.46 \\
\hline \multirow{3}{*}{$\begin{array}{l}\text { High } \\
\text { speed } \\
\text { roads } \\
>\mathbf{3 0} \mathrm{mph}\end{array}$} & Observed & Expected & Observed & Expected & \multirow{2}{*}{236} \\
\hline & 129 & 139.09 & 107 & 96.91 & \\
\hline & \multicolumn{2}{|c|}{$X^{2}=0.66$} & \multicolumn{2}{|c|}{$X^{2}=0.95$} & 1.62 \\
\hline $\begin{array}{c}\text { Total } \\
\text { observed }\end{array}$ & \multicolumn{2}{|c|}{633} & \multicolumn{2}{|c|}{441} & 1074 \\
\hline $\begin{array}{c}\text { Total Chi } \\
\text { square } \\
\text { values }\end{array}$ & \multicolumn{2}{|c|}{$X^{2}=0.85$} & \multicolumn{2}{|c|}{$\mathrm{X}^{2}=1.22$} & 2.07 \\
\hline
\end{tabular}

\subsection{The relationship between lighting conditions and} speed limits:

Another significant relationship between the lighting conditions and the speed limits was investigated in this study. As shown in figure 7, by comparing the accidents reported in lighting conditions we can state that in low speed roads the proportion of accidents occurred in dark conditions is approximately $35 \%$ and the same proportion for high speed roads is $29.66 \%$.

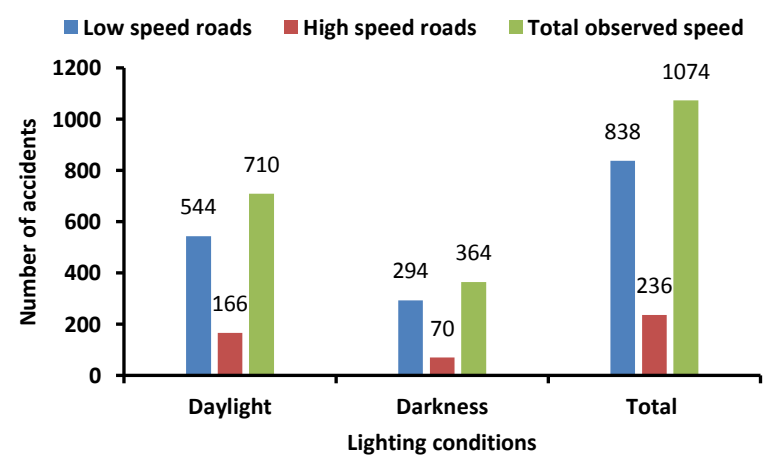

Figure 7: Lighting conditions versus speed limit at bend roads.

Apparently, these accidents proportions have a difference of $5.34 \%$ which roughly shows that in low speed roads it is more likely for an accident to occur during the night. However, the Chi-square test concludes that there is no significant effect at 5\% level of confidence (calculated $\mathrm{X}^{2}<3.84$ ) as shown in table 4.

Table 4: The relationship between lighting conditions and speed limits in bend roads.

\begin{tabular}{|c|c|c|c|c|c|}
\hline Speed & \multicolumn{2}{|c|}{ Daylight } & \multicolumn{2}{|c|}{ Darkness } & Total \\
\hline \multirow{3}{*}{$\begin{array}{c}\text { Low } \\
\text { speed } \\
\text { roads } \\
\leq 30 \mathrm{mph}\end{array}$} & Observed & Expected & Observed & Expected & \multirow{2}{*}{838} \\
\hline & 544 & 553.98 & 294 & 284.02 & \\
\hline & \multicolumn{2}{|c|}{$X^{2}=0.18$} & \multicolumn{2}{|c|}{$X^{2}=0.35$} & 0.53 \\
\hline \multirow{3}{*}{$\begin{array}{l}\text { High } \\
\text { speed } \\
\text { roads } \\
>30 \mathrm{mph}\end{array}$} & Observed & Expected & Observed & Expected & \multirow{2}{*}{236} \\
\hline & 166 & 156.02 & 70 & 79.98 & \\
\hline & \multicolumn{2}{|c|}{$X^{2}=0.64$} & \multicolumn{2}{|c|}{$X^{2}=1.23$} & 1.87 \\
\hline $\begin{array}{c}\text { Total } \\
\text { observed }\end{array}$ & \multicolumn{2}{|c|}{710} & \multicolumn{2}{|c|}{364} & 1074 \\
\hline $\begin{array}{c}\text { Total Chi } \\
\text { square } \\
\text { values }\end{array}$ & \multicolumn{2}{|c|}{$X^{2}=0.82$} & \multicolumn{2}{|c|}{$X^{2}=1.58$} & 2.40 \\
\hline
\end{tabular}

4.6 The relationship between road surface conditions and skidding at bend roads:

For emergency situations such as stopping or sudden braking, road-tyre friction is a crucial aspect. Research have statistically found a substantial negative relationship between wet surfaces and accident rates in term of skid resistance values. From the reported vehicle accidents sheets, the effect of skid resistance and road surface conditions on the observed number of vehicles involving in accidents can be shown in figure 8 . It can be noticed that the $25 \%$ of vehicle accidents on wet surfaces were due to the skidding issue. 


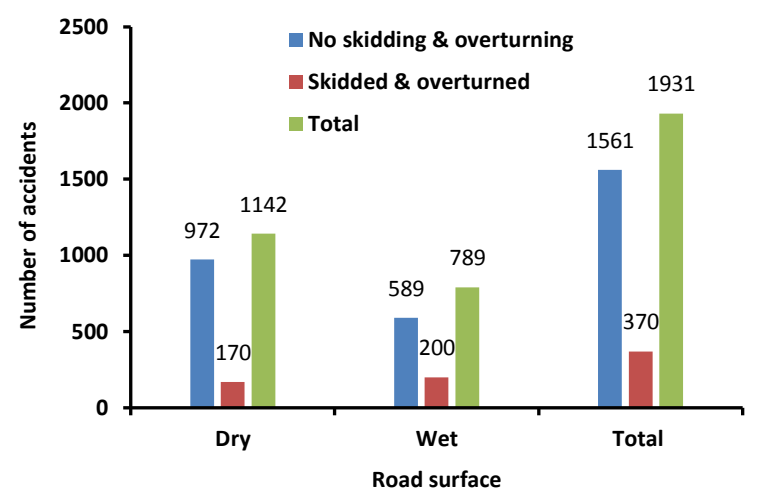

Figure 8: Number of vehicles involving in accidents due to skid resistance factor under wet and dry road conditions.

Now, the question 'Is there any significant association between the skidding and road surface conditions?'. To find out the answer, the Chi-Square test has been applied as shown in table 5 below. At 5\% level of confidence, the result showed that there is a significant association between road surface conditions and skidding at curved locations.

Table 5: The relationship between road surface conditions and skidding on bend roads.

\begin{tabular}{|c|c|c|c|c|c|}
\hline Skidding & \multicolumn{2}{|c|}{ Dry road surface } & \multicolumn{2}{|c|}{ Wet road surface } & Total \\
\hline \multirow{3}{*}{$\begin{array}{c}\text { No skidding } \\
\text { and } \\
\text { overturning }\end{array}$} & Observed & Expected & Observed & Expected & \multirow{2}{*}{1561} \\
\hline & 972 & 923.18 & 589 & 637.82 & \\
\hline & \multicolumn{2}{|c|}{$\mathrm{X}^{2}=2.58$} & \multicolumn{2}{|c|}{$X^{2}=3.74$} & 6.32 \\
\hline \multirow{3}{*}{$\begin{array}{c}\text { Skidded and } \\
\text { overturned }\end{array}$} & Observed & Expected & Observed & Expected & \multirow{2}{*}{370} \\
\hline & 170 & 218.82 & 200 & 151.18 & \\
\hline & \multicolumn{2}{|c|}{$X^{2}=10.89$} & \multicolumn{2}{|c|}{$X^{2}=15.76$} & 26.65 \\
\hline $\begin{array}{c}\text { Total } \\
\text { observed }\end{array}$ & \multicolumn{2}{|c|}{1142} & \multicolumn{2}{|c|}{789} & 1931 \\
\hline $\begin{array}{l}\text { Total Chi } \\
\text { square } \\
\text { values }\end{array}$ & \multicolumn{2}{|c|}{$X^{2}=13.47$} & \multicolumn{2}{|c|}{$X^{2}=19.50$} & 32.97 \\
\hline
\end{tabular}

\subsection{Other accidents' contributory factors at bend} roads:

Overall, traffic accident is a major problem to the society. Despite the fact that these accidents increase the risk of fatality and injuries, it is necessary to investigate in depth what other factors can associate with these accidents.

Based on real data, a comparison study was carried out by Wetteland and Lundebye [19] who stated that human error was a major factor in $73 \%$ of crashes in the UK. This percent was $6 \%$ more than that of the US as shown in figure 9.

Therefore, further analysis of accidents data including human behaviour factor was conducted in order to understand how did these accidents happened under adverse weather conditions on bend roads.

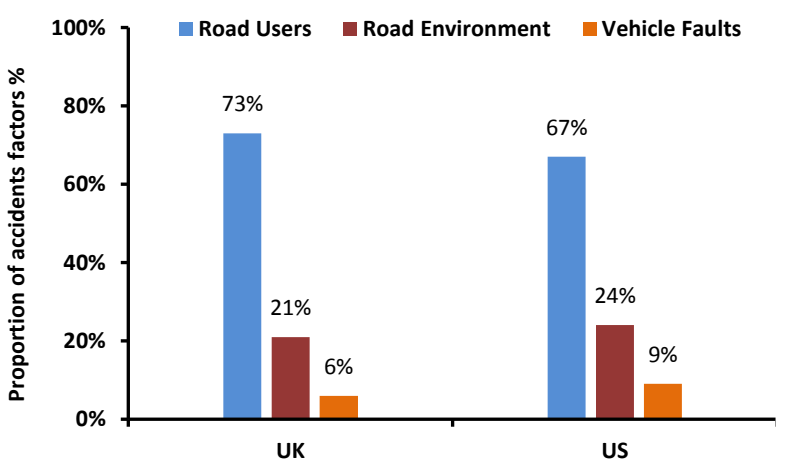

Figure 9: Percentages of accident contributing factors based on the UK and US studies

The reported accidents in bend roads revealed that only $3 \%$ of these accidents were caused by road environments and vehicle errors such as defective traffic signals. This low trend can be explained the high levels of road safety including road maintenance and improvement in accident prevention schemes. Table 6 shows that all observations and proportions of human or driver errors on wet and dry surface at bend locations over the 5 years between 2011 and 2015 at Greater Manchester.

Table 6: Human errors at bend locations.

\begin{tabular}{|l|c|c|c|c|}
\hline \multirow{2}{*}{\multicolumn{2}{|c|}{ Human errors }} & \multicolumn{4}{c|}{ Road surface conditions } \\
\cline { 2 - 5 } & \multicolumn{2}{|c|}{ Dry } & \multicolumn{2}{c|}{ Wet } \\
\cline { 2 - 5 } & F & F\% & F & F\% \\
\hline Failed to look properly & 179 & 0.22 & 90 & 0.18 \\
\hline $\begin{array}{l}\text { Careless/ reckless/ in a hurry/ } \\
\text { nervous/ uncertain/ panic }\end{array}$ & 138 & 0.17 & 69 & 0.14 \\
\hline Poor turning or manouver & 138 & 0.17 & 72 & 0.15 \\
\hline Loss of control & 132 & 0.16 & 123 & 0.25 \\
\hline $\begin{array}{l}\text { Failed to judge other vehicle } \\
\text { path or vehicle speed }\end{array}$ & 99 & 0.12 & 43 & 0.09 \\
\hline Aggressive driving & 59 & 0.07 & 33 & 0.07 \\
\hline Inexperienced driver & 42 & 0.05 & 35 & 0.07 \\
\hline Sudden braking & 22 & 0.03 & 17 & 0.03 \\
\hline Following too close & 7 & 0.01 & 4 & 0.01 \\
\hline $\begin{array}{l}\text { Failed to signal/misleading } \\
\text { signal }\end{array}$ & 5 & 0.01 & 4 & 0.01 \\
\hline $\begin{array}{l}\text { Driving too slow for } \\
\text { conditions or slow vehicle. }\end{array}$ & 1 & 0.00 & 0 & 0.00 \\
\hline \multicolumn{1}{|c|}{ Total } & $\mathbf{8 2 2}$ & $\mathbf{1 . 0 0}$ & $\mathbf{4 7 7}$ & $\mathbf{1 . 0 0}$ \\
\hline
\end{tabular}

The results demonstration that the majority of accidents on bend roads was loss of control (25\%) on wet surfaces, following by failed to look properly (22\%) on dry surfaces. We also got similar percentages for poor turning and driver aggressive behaviour on both surfaces such as nervous, careless and in a hurry behaviour. 


\section{CONCLUSION}

This paper described the analysis of accidents data in Greater Manchester reported by police involving hazardous locations from 2011 to 2015 . This is in order to understand the common accidents and contributory factors. The data was obtained from STATS19 forms including accident, vehicles and causalities information. The analysis was focused on the association between road surface and some important variables such as lighting conditions, speed limits and severity of accidents, were investigated by Chi-square test. The conclusions drawn from this study can be summarised as following:

- There is no significant association between road surface and number of casualities under different weather conditions. However, the analysis highlighted that the number of accidents on wet surfaces is around $40 \%$ of the total fatal, serious, and slight injury accidents.

- The risk of accidents during daytime are greater than night. This is affected by traffic volume at peak hours and also driving attitude.

- Speeding is a major contributory factors in accident occurrence. The situation may result in accident with the oncoming vehicle while lane changing or braking suddenly to avoid collision.

- Skid resistance is an importatnt aspect for stopping conditions particularly at wet surfaces. This is because the fact that the friction decreses when the pavement becomes wetted. The analysis showed a substational assocation between the occurrence of accidents and the surface conditions.

- Despit the fact that many contributory factors on accidents were known and recognised, there is still a need to investigate the driver behaviour factor. From data obtained, the analysis showed that more than $95 \%$ of these accidents were caused by road users' errors such as failing to look properly, aggressive driving, poor manouver and losing control. While the rest were occurred either because of vehicles faults or road environments.

- From the obtained accident data the analysis considers 1074 accidents on bends over the period from 2011 to 2015 . About $41 \%$ of these accidents were occurred on wet roads. This percent is very worrying and can indicate a problem in safety issue.

Therefore, furthur research are required to identify more effective solutions. For example, effect of temperature on skid resistance contributed to traffic accidents at bends roads, and driver behaviour approaching bend roads.

\section{REFERENCE}

[1] T. Assum, Bjørnskau et al. "Risk compensation - the case of road lighting." Accident Analysis \& Prevention 31(5): 545-553, 1999.

[2] M. Bassani, Catani et al. "Night-time and daytime operating speed distribution in urban arterials." Transportation Research Part F: Traffic Psychology and Behaviour, 2016.

[3] M. E. Campbell, "The wet-pavement accident problem: Breaking through. Traffic Quarterly." 25, 1971.

[4] Department for Transport. "Reported Road Casualties Great Britain: Annual Report", 2014.

[5] J. B. Edwards, "Weather-related road accidents in England and Wales: a spatial analysis." Journal of Transport Geography 4(3): 201-212, 1996.

[6] T. Fu, "Effects of Adverse Winter Weather Conditions on Highway Traffic and Driver Behaviors.", 2013.

[7] P. Greibe, "Braking distance, friction and behaviour." Findings, analyses and recomendations based on braking trials. [Brzdná dráha, trenie a správanie sa. Zistenia, analýzy a odporúčania založené na brzných skúškach]. Lyngby: Trafitec, 2007.

[8] L. W. Hatherly and A. E. Young. "The location and treatment of urban skidding hazard sites." Transportation Research Record 623: 21-28, 1977.

[9] K. Keay and I. Simmonds. "Road accidents and rainfall in a large Australian city." Accident Analysis \& Prevention 38(3): 445-454, 2006.

[10] M. Kilpeläinen and H. Summala. "Effects of weather and weather forecasts on driver behaviour." Transportation Research Part F: Traffic Psychology and Behaviour 10(4): 288299, 2007.

[11] M. P. M. Mathijssen and R. Maas. "Wet-weather accidents. What can road authorities do about them? ", 1979.

[12] P. Mondal, Sharma et al. "Are Road Accidents Affected by Rainfall? A Case Study from a Large Indian Metropolitan City." British Journal of Applied Science \& Technology 1(2): 16, 2011.

[13] B. Nambuusi, et al. "A review of accident prediction models for road intersections.", 2008.

[14] S. Newstead, C. M. Delaney, A. L. Watson "Quality criteria for the safety assessment of cars based on real word crashes. ", 241, 2006.

[15] J. M. Pardillo Mayora and R. Jurado Piña. "An assessment of the skid resistance effect on traffic 
safety under wet-pavement conditions." Accident Analysis \& Prevention 41(4): 881-886, 2009.

[16] P. Rämä, "Effects of weather-controlled variable message signing on driver behaviour.", Technical Research Centre of Finland, 2001.

[17] H. Summala, "Brake reaction times and driver behavior analysis." Transportation Human Factors 2(3): 217-226, 2000.

[18] Y. B. Wah, et al. "Decision tree model for count data.", Proceedings of the World Congress on Engineering, 2012.

[19] T. Wetteland and S. Lundebye. "Financing of road safety actions: third African road safety congress." Pretoria, South Africa, World Bank Washington DC, USA, 1997.

[20] World Health Organization. "Global status report on road safety". Printed in Italy, 2015.

\section{ACKNOWLEDGMENTS}

This paper was written by the authors as part of $\mathrm{PhD}$ and MSc theses for the University of Salford in the UK. This paper includes road traffic accidents database reported by the police using STATS19 forms in Greater Manchester - UK for the years from 2011 to 2015. The authors would express their deep gratitude and sincere thanks to the supervisor Senior Lecturer Mr. Ralph Henson, for his invaluable advice, active encouragement, and guidance throughout this study.

\section{BIOGRAPHY}

Karzan S. Ismael:

I received BSc in Engineering Urban Planning from Sulaimani Polytechnic University in 2012; MSc. in Transport Engineering and Planning at the University of Salford /United Kingdom in 2016. Currently, I am working as Lecturer at Sulaimani Polytechnic University/ Engineering City Planning Department.

\section{Noorance A. Razzaq:}

I graduated from Baghdad University with the BSc in Civil Engineering in 2001 followed by the MSc in Transportation Engineering in 2005. I have worked as lecturer in the Civil Engineering Department at the University of Al-Muthanna since 2006. Currently, I am a $\mathrm{PhD}$ candidate at the University of Salford and sponsored by the Iraqi Ministry of Higher Education and Scientific Research since 2014. 